\title{
RANCANG BANGUN APLIKASI MONITORING ANAK DI PONDOK PESANTREN TAFRIIJUL AHKAM CIKIRAY BERBASIS ANDROID
}

\author{
Rizki Fatullah', Ma'sum ${ }^{2}$, Ma'mun Amri $^{3}$ \\ ${ }^{1,2,3}$ Fakultas Ilmu Komputer Universitas Banten Jaya \\ Jl Syech Nawawi Albantani Kp. Boru, Kec. Curug, Kota Serang, Banten \\ E-mail: rizkifath@unbaja.ac.id ${ }^{1}$, masum.unbaja@gmail.com², \\ mamunamri97@gmail.com ${ }^{3}$
}

\begin{abstract}
This research was conducted to make it easier for parents to get fast and realtimeactivity information, plus the lack of data storage on student activity by caregivers. In this modern era, the development of technology is increasing rapidly so that everything is computerized, so the cottage needs to follow the development of this modern era, so that the work in the cottage will be easy and reduce errors due to human error. As technology develops, website-based applications for child monitoring have started to emerge, but parents are already using smartphones a lot, with the existence of Android-based applications, it is hoped that it can be used as a monitoring medium for children that can be accessed by all parents who leave their children at the Tafriijul Islamic boarding school. Ahkam Cikiray effectively and efficiently. This application uses the waterfall method and uses UML (Unified Modeling Language) for visual modeling systems. The data collection process was carried out by interviewing the boarding school. The conclusion of making this application is to make it easier for the guardian of students to receive information on weekly, monthly, yearly activities and this system makes it easier for teachers at the Tafriijul Ahkam Islamic boarding school to provide information on activities, achievements, memorization of the Qur'an, violations of spp payments and payment of re-registration to parents, so the lodge does not spend a lot of money to provide information on student activities by letter.
\end{abstract}

Keywords: Android, Monitoring, Pesantren, UML, Waterfall

\section{PENDAHULUAN}

Pada era modern ini perkembangan teknologi semakin pesat sehingga segala sesuatu pekerjaan sudah terkomputerisasi, maka pondok pesantren perlu mengikuti perkembangan era modern ini, sehingga pekerja yang ada di pondok pesantren akan mudah dan mengurangi kesalahan akibat human error, ditambah lagi lemahnya penyimpanan data aktivitas santri oleh pengasuh. Santri yang ada di pondok pesantren sudah seharusnya di monitor aktivitasnya, sudah kewajiban pesantren untuk melaporkan aktivitas santri guna untuk menambah kepercayaan orang tua terhadap pondok pesantren. Seiring perkembangan teknologi maka banyak yang membuat aplikasi berbasis website tentang monitoring anak ini, akan 
tetapi banyak di kalangan orang tua dan bahkan seluruh manusia sudah banyak menggunakan smartphone, maka perlu ada aplikasi monitoring anak yang berbasis Android. Pondok pesantren Tafriijul Ahkam Cikiray merupakan salah satu pondok modern yang ada di Rangkasbitung. Pondok pesantren Tafriijul Ahkam didirikan tepatnya tanggal 15 Juni 2003. yang dipimpin oleh KH. Adang Jazuli, S.HI yang memiliki 3 madrasah. Pondok pesantren memiliki santri kurang lebih 296 Santri dan 32 Guru sehingga pondok pesantren kesulitan dalam mendata aktivitas santri khususnya pengasuhan, maka pihak lembaga perlu mengadakan sebuah aplikasi yang bisa menunjang permasalahan yang ada. Penelitian menurut (Deval Gusrion 2019) dengan judul Aplikasi Monitoring Aktivitas Santri Berbasis Android (Studi Kasus : Pesantren Modern Ulul Al-Bab Makassar) Memerlukan data antara lain Berbasis Android, Monitor Aktivitas Santri, Monitor Kegiatan Ekstrakurikuler, Monitor informasi Secara Real Time. Penelitian menurut (Budi Utomo 2017) dengan judul Sistem Pemantauan Siswa Sekolah Berbasis Web (Studi Kasus: Pondok Pesantren Darul Muttaqien) Memerlukan data antara lain Berbasis Website, Monitor Kegiatan Akademik, Monitor Nilai Akademik, Monitor Absensi. Penelitian menurut (Muhamad Sabar dkk 2017) dengan judul Sistem informasi Monitoring Kegiatan Santri Berbasis Android Studi Kasus : Pesantren Al-Hidayah Garut dengan pembahasan Berbasis Android, Monitor Kegiatan Santri, Monitor Absensi Santri, Monitor Pelanggaran Santri. Dengan adanya permasalahan diatas, maka penulis akan merancang suatu aplikasi Monitoring yang berjudul "Rancang Bangun Aplikasi Monitoring Anak di pondok pesantren Tafriijul Ahkam Cikiray Berbasis Android". Dengan adanya aplikasi ini, diharapkan dapat dimanfaatkan sebagai media monitoring anak yang dapat diakses oleh semua orang tua yang menitipkan anaknya di pondok pesantren Tafriijul Ahkam Cikiray secara realtime dan agar segala sesuatu yang terjadi dalam pesantren tidak semerta-merta disalahkan kepada pihak pesantren karena dengan monitoring ini pihak orang tua dapat mengontrol aktivitas, hafalan alqur'an, pelanggaran, prestasi, dan pembayaran SPP anaknya dari jauh. 


\section{METODE PENELITIAN}

\section{Metode Pengumpulan Data}

Penelitian ini dilakukan di Pondok Pesantren Tafriijul Ahkam Cikiray dan metode pengumpulan data yang digunakan adalah:

a. Observasi: pengumpulan data yang tidak hanya mengukur sikap dari responden namun juga dapat digunakan untuk merekam berbagai fenomena yang terjadi.

b. Interview: pengumpulan data yang dilakukan melalui tatap muka dan tanya jawab langsung.

c. Research: pengumpulan data dengan mengambil data dari berbagai sumber.

\section{Metode Analisa dan Perancangan}

Metode penelitian yang diterapkan pada penelitian ini adalah dengan pengembangan metode waterfall. Karena metode waterfall merupakan model pengembangan sistem informasi yang sistematik dan sekuensial. Metode waterfall adalah suatu proses pengembangan perangkat lunak berurutan, di mana kemajuan dipandang sebagai terus mengalir ke bawah (seperti air terjun) melewati fase-fase perencanaan, pemodelan, implementasi (konstruksi), dan pengujian. Pengembangan perangkat lunak berurutan/ linear:

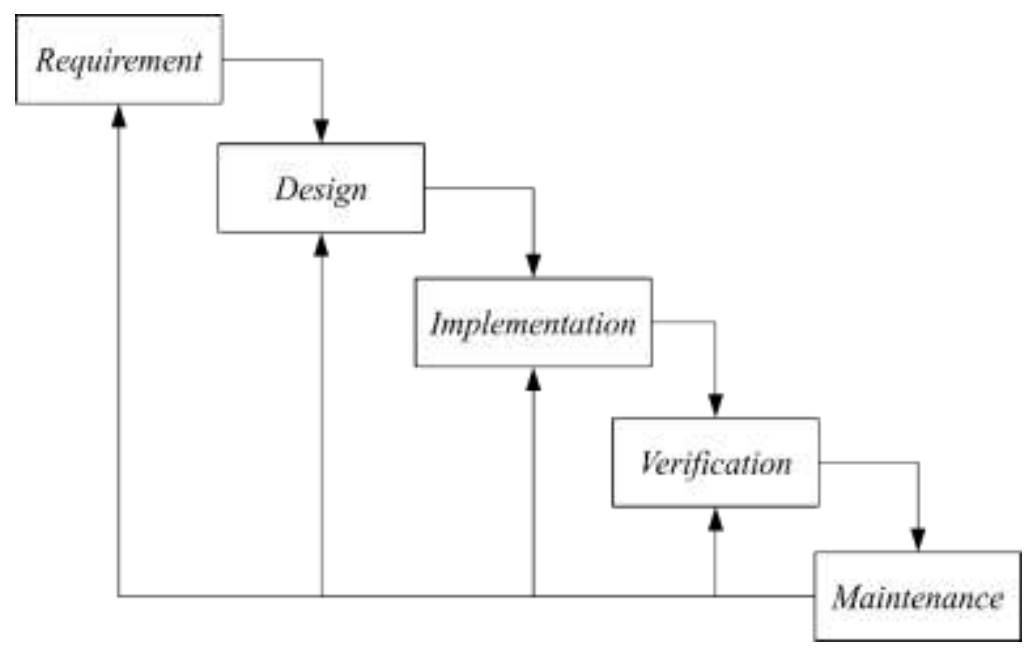

Gambar 1. Diagram Alir Metode Waterfall

Dalam pengembangannya, metode waterfall memiliki beberapa tahapan yang berurut yaitu : 


\section{a. Requirement Analysis (Analisis kebutuhan)}

Penulis sebagai developer melakukan wawancara dan observasi untuk menemukan letak permasalahan yang ada pada sistem yang berjalan, kebutuhan sistem dan solusi untuk mengatasi permasalahan yang ada pada sistem yang berjalan. Penulis melakukan wawancara dengan kepala pondok bapak Deden Jaya, S.Pd dan kepala bagian Majlis Pembimbing Organisasi Bapak Faturrahman, setelah melakukan wawancara penulis mendapat informasi mengenai alur dari sistem yang berjalan dan hal yang dibutuhkan oleh pondok pesantren untuk membangun sistem informasi monitoring anak secara realtime.

b. System Design (Desain sistem)

Pada tahap ini penulis mengadaptasi hasil dari analisis kebutuhan dalam bentuk desain, diantaranya UML yang digunakan untuk pemodelan perangkat lunak agar lebih mudah diimplementasikan kedalam sistem. Kemudian untuk perancangan database penulis menggunakan Firebase dan untuk memberi gambaran penulis membuat desain interface menggunakan wireframe.

c. Coding \& Testing (Penulisan kode program / implementation)

Setelah melalui tahap analisis dan desain selanjutnya masuk kedalam tahap pembuatan kode program yaitu penulis mengimplementasikan rancangan program dalam bentuk desain ke dalam source code Kotlin, sehingga semua fungsi dapat dijalankan oleh pengguna.

d. Integration \& Testing (Penerapan / Pengujian Program)

Pada tahap ini penulis melakukan pengujian terhadap sistem yang bertujuan untuk mengevaluasi atribut-atribut atau fungsionalitas sebuah sistem apakah sesuai dengan kebutuhan yang diinginkan, metode yang digunakan dalam pengujian yaitu black box.

e. Operation \& Maintenance (Pemeliharaan)

Tahap terakhir yaitu pendukung dan pemeliharaan melakukan pemeliharaan secara berkala dimulai dari mencadangkan database, perubahan struktur hardware, dan update fitur pada sistem. 


\section{HASIL DAN PEMBAHASAN}

Sistem Monitoring anak di Pondok Pesantren Tafriijul Ahkam Cikiray perlu dibuatkan demi menjadi daya tarik wali santri dan memudahkannya dalam mengetahui perkembangan anaknya dipesantren, dengan cara wali kelas mencatat kegiatan sehari-harinya, kedisiplinannya dalam mentaati peraturan pondok dan informasi pembayaran spp di pondok pesantren pada setiap bulannya dengan cepat dan realtime.

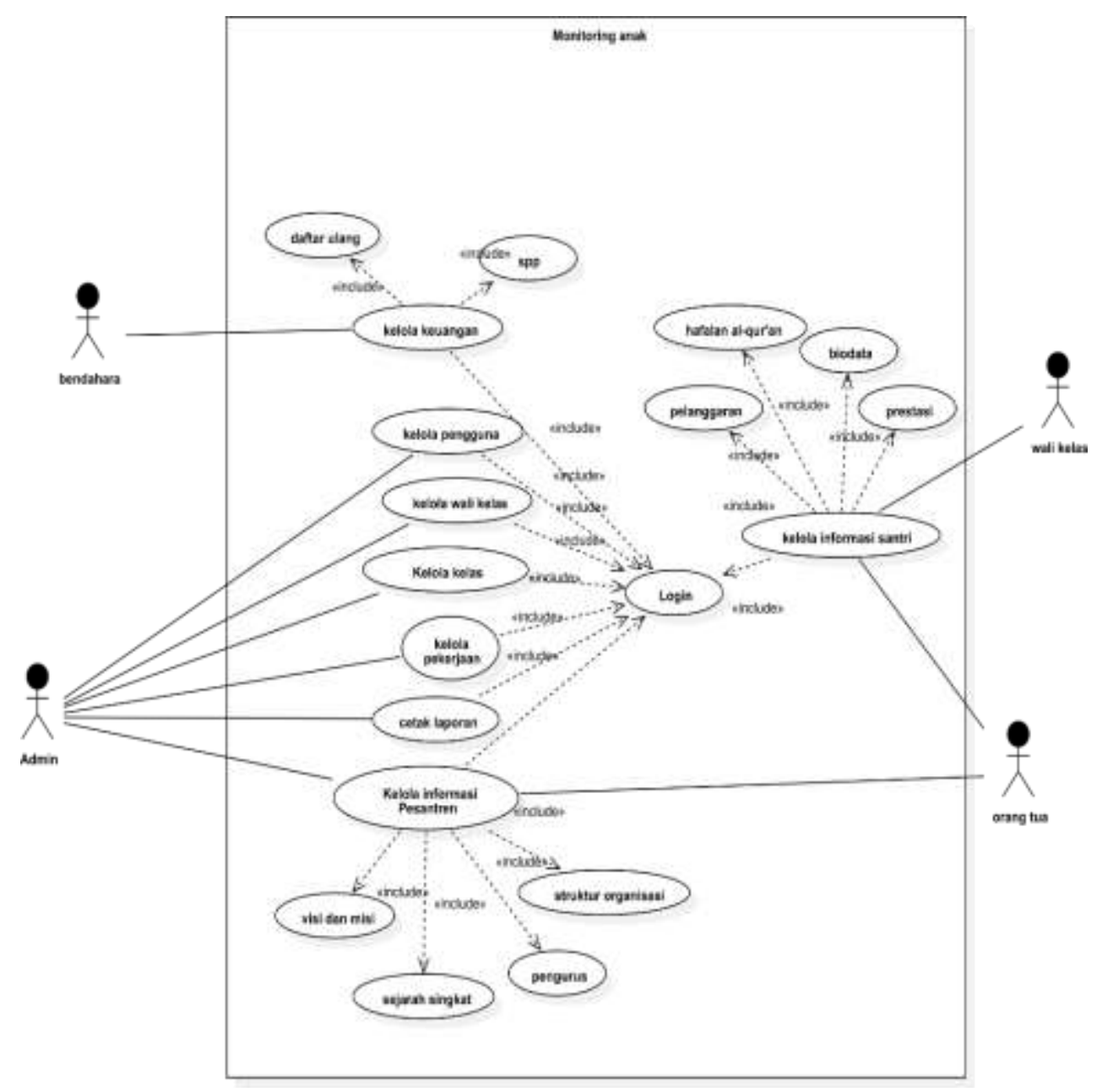

Gambar 2. Usecase Diagram Sistem 


\section{Kamus Data}

Tabel 1 Admin

\begin{tabular}{|c|l|c|c|}
\hline No & \multicolumn{1}{|c|}{ Field } & Type & Keterangan \\
\hline 1 & Nip & string & No induk pendidik \\
\hline 2 & Email & String & Email admin \\
\hline 3 & password & String & Kata sandi admin \\
\hline 4 & Nama & String & Nama admin \\
\hline 5 & jenis_kelamin & String & Jenis kelamin \\
\hline 6 & agama & String & Agama admin \\
\hline 7 & no_telp & String & No telpon \\
\hline 8 & alamat & String & Alamat admin \\
\hline 9 & Kelas & String & Kelas admin \\
\hline 10 & Status & String & Status admin \\
\hline 11 & photoUrl & string & foto profil \\
\hline 12 & photoName & string & nama foto \\
\hline
\end{tabular}

Tabel 2 Ustadz

\begin{tabular}{|c|l|c|c|}
\hline No & \multicolumn{1}{|c|}{ Field } & Type & Keterangan \\
\hline 1 & Nip & Int & No induk pendidik \\
\hline 2 & Email & String & Email ustadz \\
\hline 3 & password & String & Kata sandi ustadz \\
\hline 4 & Nama & String & Nama ustadz \\
\hline 5 & jenis_kelamin & String & Jenis kelamin \\
\hline 6 & agama & String & Agama ustadz \\
\hline 7 & no_telp & String & No telpon \\
\hline 8 & alamat & String & Alamat ustadz \\
\hline 9 & Kelas & String & Kelas ustadz \\
\hline 10 & Status & String & Status ustadz \\
\hline 11 & photoUrl & string & foto profil \\
\hline 12 & photoName & string & nama foto \\
\hline
\end{tabular}


Tabel 3 Santri

\begin{tabular}{|c|l|c|c|}
\hline No & \multicolumn{1}{|c|}{ Field } & Type & Keterangan \\
\hline 1 & nip & string & No induk pendidik \\
\hline 2 & Email & String & Email \\
\hline 3 & password & String & Kata sandi \\
\hline 4 & nama & String & Nama \\
\hline 5 & jenis_kelamin & String & Jenis kelamin \\
\hline 6 & agama & String & Agama \\
\hline 7 & no_telp & String & No telpon \\
\hline 8 & alamat & String & Alamat \\
\hline 9 & kelas & String & Kelas \\
\hline 10 & status & String & Status \\
\hline 11 & tmp_lahir & String & Tempat lahir \\
\hline 12 & tgl_lahir & String & Tanggal lahir \\
\hline 13 & nama_ayah & String & Nama ayah \\
\hline 14 & nama_ibu & String & Nama ibu \\
\hline 15 & pk_ayah & String & Pekerjaan ayah \\
\hline 16 & pk_ibu & String & Pekerjaan ibu \\
\hline 17 & photoUrl & string & foto profil \\
\hline 18 & photoName & string & nama foto \\
\hline
\end{tabular}

Tabel 4 Wali Kelas

\begin{tabular}{|c|l|c|c|}
\hline No & \multicolumn{1}{|c|}{ Field } & Type & Keterangan \\
\hline 1 & Nip & string & No induk pendidik \\
\hline 2 & Nama & String & Nama wali kelas \\
\hline 3 & thn_akhir_ajaran & String & Akhir periode \\
\hline 4 & thn_awal_ajaran & String & Awal periode \\
\hline 5 & kelas & string & kelas \\
\hline
\end{tabular}

Tabel 5 Hafidz

\begin{tabular}{|c|l|c|c|}
\hline No & \multicolumn{1}{|c|}{ Field } & Type & Keterangan \\
\hline 1 & Nip & Int & No induk pendidik \\
\hline 2 & Ayat & String & Ayat yang di hafal \\
\hline 3 & Surat & String & Surat al-qur'an \\
\hline 4 & tanggal & String & Tanggal menghafal \\
\hline
\end{tabular}


Tabel 6 Prestasi

\begin{tabular}{|c|l|c|c|}
\hline No & \multicolumn{1}{|c|}{ Field } & Type & Keterangan \\
\hline 1 & Nip & Int & No induk pendidik \\
\hline 2 & Kelas & String & Kelas santri \\
\hline 3 & prestasi & String & Pretasi yang di raih \\
\hline 4 & tanggal & String & Tanggal prestasi \\
\hline
\end{tabular}

Tabel 7 Pelanggaran

\begin{tabular}{|c|l|c|c|}
\hline No & \multicolumn{1}{|c|}{ Field } & Type & Keterangan \\
\hline 1 & Nip & Int & No induk pendidik \\
\hline 2 & Jenis & String & Jenis pelanggaran \\
\hline 3 & pelanggaran & String & Pelanggaran yang dilakukan \\
\hline 4 & Tanggal & String & Tanggal dihukum \\
\hline 5 & hukuman & String & Hukuman yang diberikan \\
\hline
\end{tabular}

Tabel 8 Spp

\begin{tabular}{|c|c|c|c|}
\hline No & Field & Type & Keterangan \\
\hline 1 & nisn & string & no induk siswa nasional \\
\hline 2 & Bulan & String & Bayar Spp bulan \\
\hline 3 & Tanggal & String & Tanggal bayar \\
\hline 4 & nama & string & nama \\
\hline 5 & nominal & int & nominal uang \\
\hline 6 & kelas & string & kelas \\
\hline
\end{tabular}

Tabel 9 Aktivitas Harian

\begin{tabular}{|c|l|c|c|}
\hline No & \multicolumn{1}{|c|}{ Field } & Type & Keterangan \\
\hline 1 & nip & string & no induk pelajar \\
\hline 2 & status & String & Hadir/Tidak \\
\hline 3 & hari & string & nama hari \\
\hline 4 & kegiatan & string & jenis kegiatan \\
\hline 5 & jam_mulai & string & waktu mulai aktivitas \\
\hline 6 & jam_akhir & string & waktu akhir aktivitas \\
\hline 7 & tgl & string & Tanggal \\
\hline
\end{tabular}


Tabel 10 Aktivitas

\begin{tabular}{|c|l|c|c|}
\hline No & \multicolumn{1}{|c|}{ Field } & Type & Keterangan \\
\hline 1 & id & string & id aktivitas \\
\hline 2 & kelas & String & kelas \\
\hline 3 & namaAktivitas & string & nama \\
\hline 4 & photoUrl & string & foto aktivitas \\
\hline 5 & keterangan & string & keterangan aktivitas \\
\hline 6 & tanggal & string & tanggal \\
\hline 7 & jenis & string & Jenis \\
\hline
\end{tabular}

\section{HASIL IMPLEMENTASI SISTEM}

\section{a. Halaman Login}

Form pertama yang muncul ketika mengakses adalah login, berfungsi untuk memberikan hak akses kepada user untuk mengolah sistem yang telah disediakan.

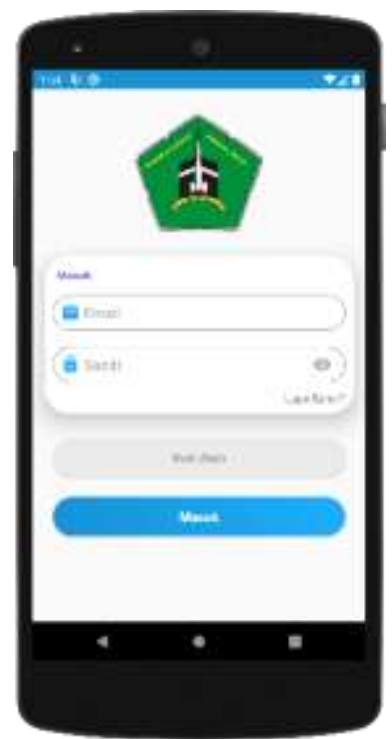

Gambar 3 Login 


\section{b. Halaman Home Admin, Orang Tua, Bendahara dan Wali Kelas}

Halaman ini adalah halaman di mana admin berhasil melewati tahap Login dan masuk ke dalam tampilan utama yaitu Home di dalamnya terdiri dari datadata informasi santri.

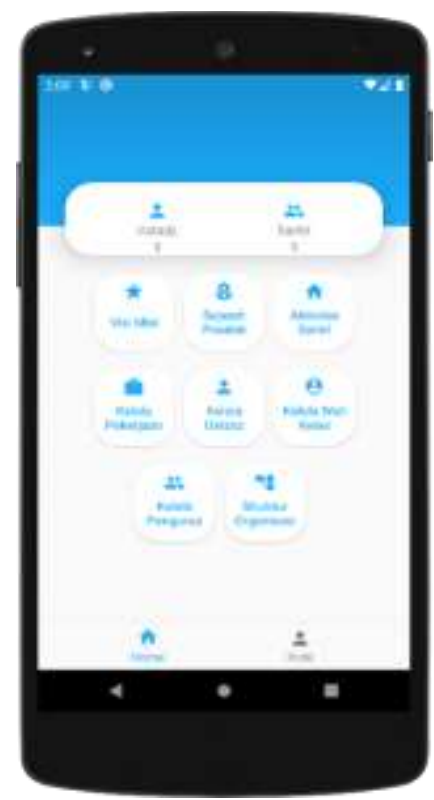

Gambar 4 Home Admin

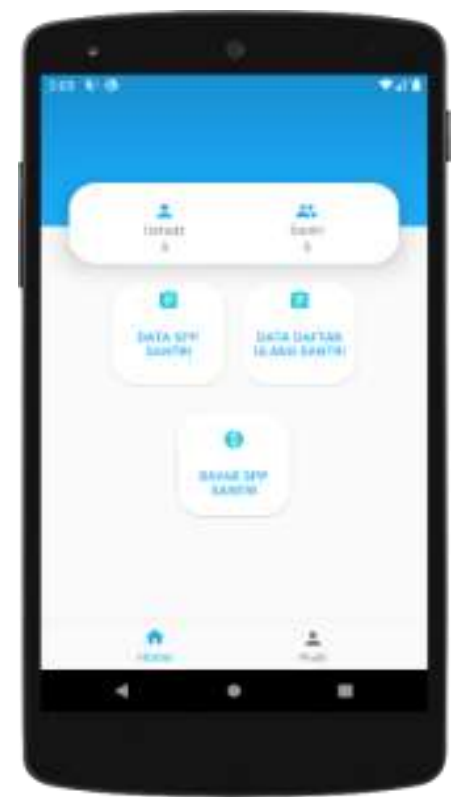

Gambar 6 Home Bendahara

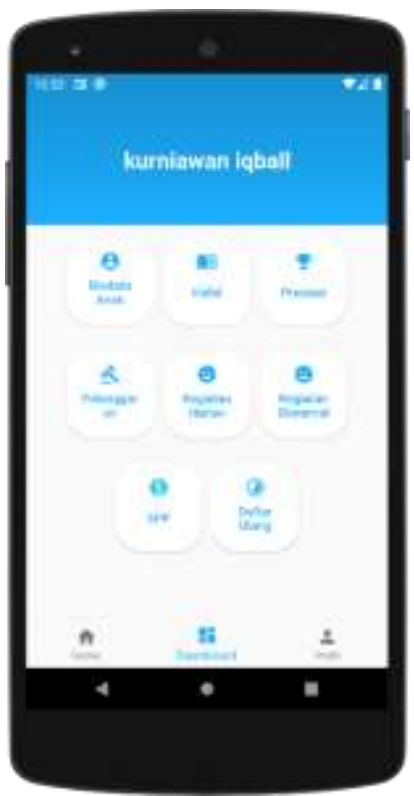

Gambar 5 Home Orang Tua

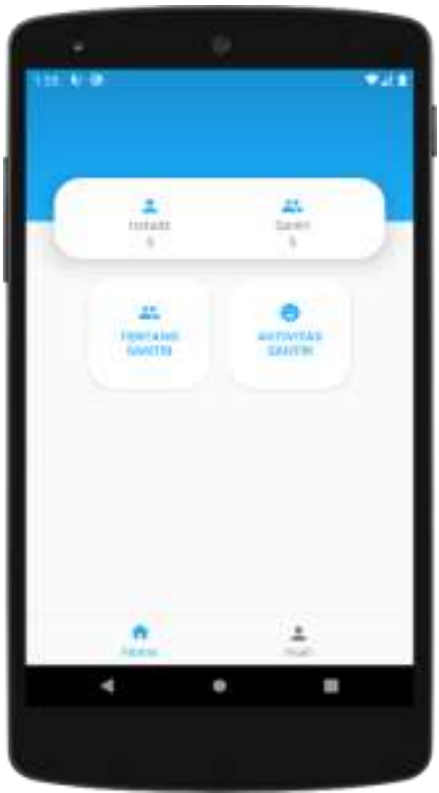

Gambar 7 Home Wali Kelas 
c. Wali Kelas Kelola Hafidz, Prestasi, Pelanggaran dan Aktivitas
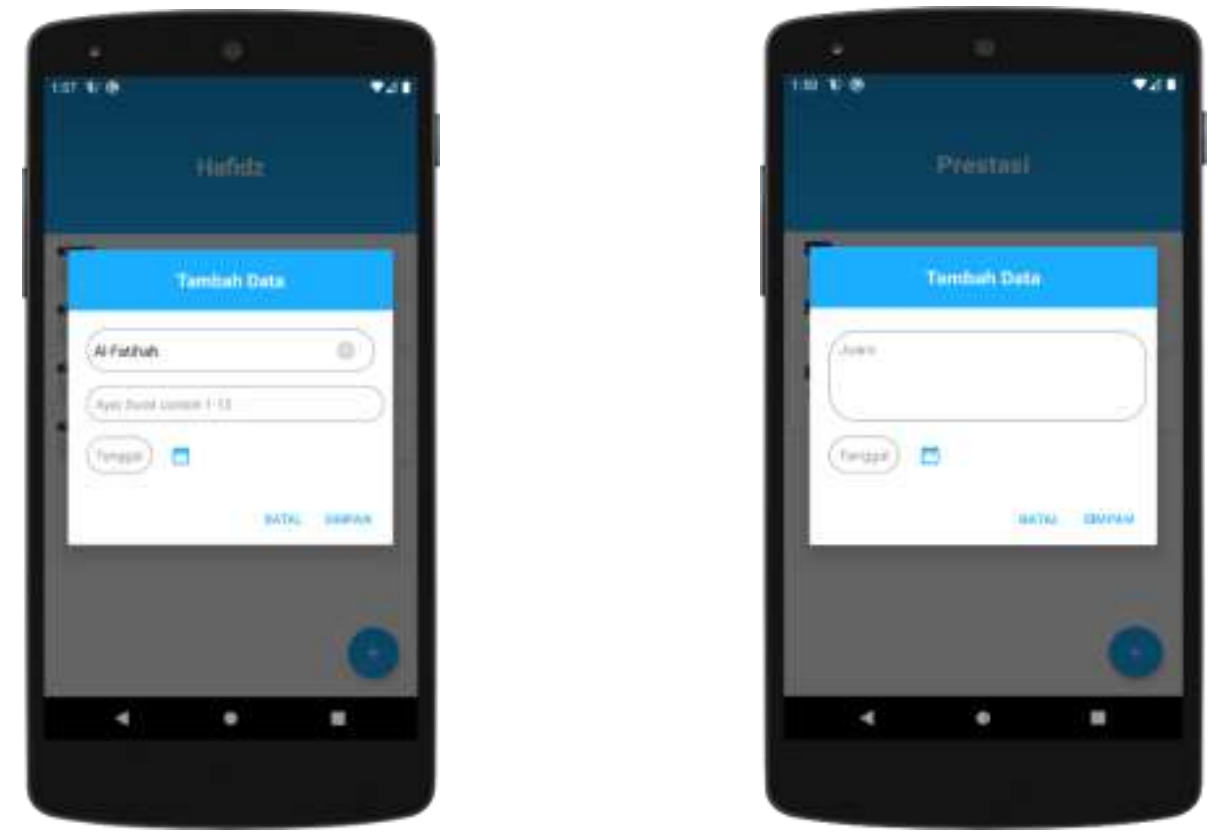

Gambar 8 Kelola Hafidz

Gambar 9 Kelola Prestasi
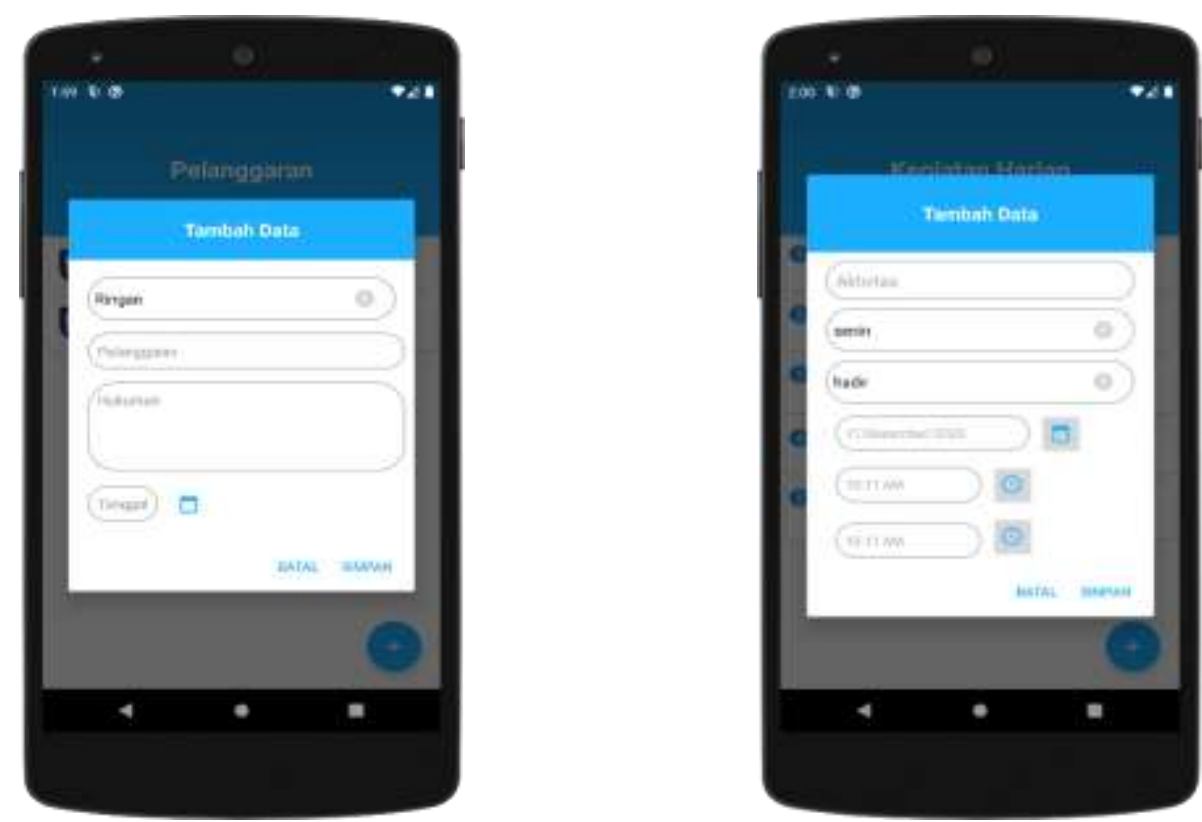

Gambar 10 Kelola Pelanggaran

Gambar 11 Kelola Aktifitas 
Jurnal Sistem Informasi dan Informatika (SIMIKA)

P-ISSN: 2622-6901

Vol.4 No.1 Tahun 2021

E-ISSN: 2622-6375

\section{d. Bendahara Kelola SPP dan Daftar Ulang}

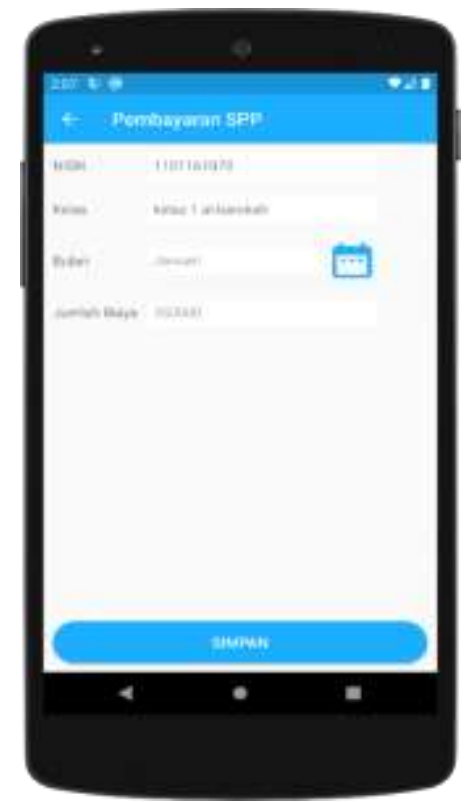

Gambar 12 Kelola SPP

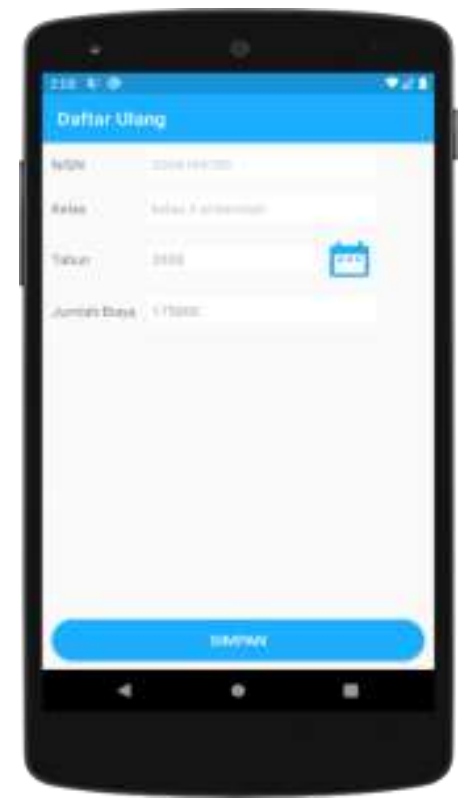

Gambar 13 Kelola Daftar Ulang

\section{e. Laporan}

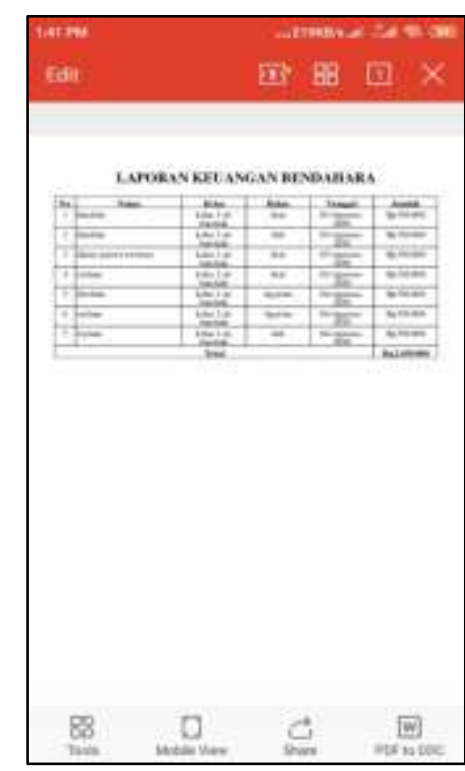

Gambar 14 Laporan Keuangan Bendahara 


\section{KESIMPULAN}

1. Seiring perkembangannya teknologi banyak banyak di kalangan orang tua sudah banyak menggunakan smartphone maka aplikasi monitoring anak berbasis Android ini mempermudah wali santri untuk menerima informasi aktivitas santri.

2. Berdasarkan hasil penelitian, aplikasi monitoring santri berbasis android yang dirancang menghasilkan informasi yang realtime dan akurat. Informasi yang dihasilkan diantaranya yaitu hafalan Al-Quran, prestasi, pelanggaran, pembayaran SPP, dan pembayaran daftar ulang.

\section{REFERENSI}

Ana Naela Nurhayati. (2017). Rancang Bangun Aplikasi Penjualan dan Pembelian Barang Pada Koperasi Kartika Samara Grawira Prabumulih. Jurnal Teknologi dan informasi (JATI), Vol.7 No.2, hal. 3

Bunga, M. S., Iryanto, I., Puspaningrum, A., \& Darmawan, M. (2019). Pengembangan Aplikasi Mobile Monitoring Anak Asuh Berbasis Android pada Lembaga Kemanusiaan Kilau Indonesia. In Prosiding Industrial Research Workshop and National Seminar (Vol. 10, No. 1, pp. 97-106).

Hidayat, M Irwan. (2016). Aplikasi Monitoring Aktivitas Santri Berbasis Android, Sistem Analisa dan Desain Perangkat Lunak.

Kusniyati, H. Sitanggang, NSP. (2016) Aplikasi Edukasi Budaya Toba Samosir Berbasis Website, Jurnal Teknik Informatika Vol. 9 No. 1.

Iad Astuti, RA Sumarni. (2017) Pengembangan Media Pembelajaran Fisika Mobile Learning berbasis. Jurnal Penelitian \& Pengembangan Pendidikan Fisika. Vol. 3, No. 1,

M Noor, A Masykurinnisa. (2017). Aplikasi Ayatul Ahkam Berbasis Web, Jurnal Sains dan Informatika, Vol. 3, No. 2, Hal. 1.

Nuryani, E., \& Romdoni, M. Y. (2020). Aplikasi Monitoring Kebersihan Sarana dan Prasarana Kampus Berbasis Web Menggunakan Teknik Responsif Pada Android. JSiI (Jurnal Sistem Informasi), 7(2), 89-96.

Syahid, S., Hidayat, S. S., Santoso, A., \& Riyadi, A. H. (2017, November). Rancang Bangun Sistem Monitoring Anak di Tempat Penitipan Anak Menggunakan Kamera CCTV Berbasis Android. In Prosiding Sentrinov (Seminar Nasional Terapan Riset Inovatif) (Vol. 3, No. 1, pp. TE293TE299). 